\title{
The structural organization of the manifestations of professional personality deformation in teachers with different levels of situational reflection
}

\author{
Galina Uvarova ${ }^{1, *}$, Nogala Shevkieva ${ }^{2}$ \\ ${ }^{1}$ Kalmyk State University named after B.B. Gorodovikova, 358000, Elista, Russia \\ ${ }^{2}$ Kalmyk State University named after B.B. Gorodovikova, 358000, Elista, Russia
}

\begin{abstract}
The study of the structural organization of the manifestations of the professional deformation of the personality of teachers with low and high level of situational reflection. Using structural psychological analysis, it was established that the structure of the manifestations of professional deformation of the personality of teachers with a low level of situational reflection is characterized by a low degree of integration of its components. For teachers with a high level of situational reflection, on the contrary, the structure of the manifestations of professional personality deformation is more consistent, the basic components that ensure the structural integration of the system - conservatism, dogmatism.
\end{abstract}

In the educational sphere, changes are taking place that are associated with the introduction of new federal state educational standards. The reform of the education system makes special demands on the personality of the teacher. The professional functioning of teachers refers to the emotionally strained form of social activity and is included in the group of professions most prone to professional deformations.

Despite the fact that the vast majority of studies of professional deformation are dedicated to teachers (V.V. Dikova, E.F. Seer, E.V. Ivanova, N.A. Korneeva, L.M. Mitina, N.B. Moskvina, O.S. Nozhenkina, O.B. Polyakova, E.E. Symanyuk, E.V. Yurchenko and others), the relevance of the study is that at the moment there are no works that would describe the features of the structural organization of the manifestations of the professional deformation of the personality of teachers with low and high levels of situational reflection.

E.F. Seer writes that professional development involves the reflection of one's state, experience [1]. O.S. Nozhenkina established the relationship between the components of professional deformation of the personality of teachers (rigidity, authoritarianism, uncriticality) with the levels of professional reflection (activity, interactive, personal) [2].

Reflection provides the regulation of activity, while the activity itself is the subject of reflection. A.V. Karpov identifies retrospective, situational (relevant) and perspective

\footnotetext{
* Corresponding author: gal.uvarova2012@yandex.ru
} 
reflection. Situational reflection involves self-control of a person's behavior in the current situation, analysis of its components, understanding of what is happening, a tendency to correlate one's actions with a specific situation and change them in accordance with these conditions and the state of the subject itself [3].

An empirical study found that with an increase in reflection from low to high, the level of severity of professional deformation of the personality decreases [4]. Overcoming professional deformation is possible only with the recognition of their personal characteristics, qualities, adverse changes in connection with professional activities.

The purpose of the study: to identify the specific structure of manifestations of professional personality deformation among teachers with different levels of situational reflection.

\section{Research hypotheses:}

1. Manifestations of professional personality deformation differ among teachers with different levels of situational reflection.

2. There are significant differences in the structural organization of the manifestations of the professional deformation of the personality of teachers with low and high levels of situational reflection.

The study involved 43 teachers aged 25 to 58 years. Work experience from 5 to 36 years $(\mathrm{M}=15.86, \mathrm{SD}=10.05), 39$ women and 4 men.

The study used the following methods: diagnostics of the level of reflexivity (A.V. Karpov, V.V. Ponomareva), a questionnaire for identifying professional deformations of teachers (E.F. Seer), a questionnaire for identifying forms of aggressive and hostile BassDarki reactions (in adaptation E. F. Seeer, E.E.Symanyuk).

Mathematical data processing: descriptive statistics, comparative statistics (MannWhitney U-test), correlation analysis (Spearman's r), structural and psychological analysis by generalized indicators of organization, integrability and differentiation index proposed by A.V. Karpov, express method for comparing matrices and structure patterns for their «homogeneity-heterogeneity» (A. V. Karpov).

At the first stage, a comparative study was conducted between teachers with a low and high level of situational reflection, whose goal was to establish differences in the severity of manifestations of professional deformation of the personality of teachers.

The analysis showed that the level of dominance $(\mathrm{p}=0,005)$, authoritarianism $(\mathrm{p}=$ $0,017)$, social hypocrisy $(p=0,023)$, conservatism $(p=0,046)$ and didacticity $(p=0,045)$ are higher for teachers with a low level of situational reflection. than teachers with a high level of situational reflection.

The revealed differences indicate that teachers who do not show the ability to thoroughly analyze their current activities and current events strive to satisfy the need for power, to suppress, use mainly orders, directions, use established teaching technologies, and template methods for transferring knowledge and experience, characterized by insincerity of feelings and relationships.

The data obtained made it possible to identify differences between individual manifestations of the professional deformation of the personality of teachers with low and high levels of situational reflection.

At the next stage of the study, a structural analysis was carried out, which made it possible to discover which particular components are of greater importance in the structure of professional deformation of the personality of teachers with different levels of situational reflection.

Matrices of inter-correlations of manifestations of professional deformation of the personality of teachers with different levels of situational reflection were calculated, based 
on which structuregrams were constructed that significantly correlated (for $\mathrm{p} \leq 0,05$ and $\mathrm{p} \leq$ $0,01)$ with each other manifestations of professional personality deformation.

Structural diagrams of manifestations of professional personality deformation of teachers with low and high level of situational reflection are presented in Figures 1 and 2.

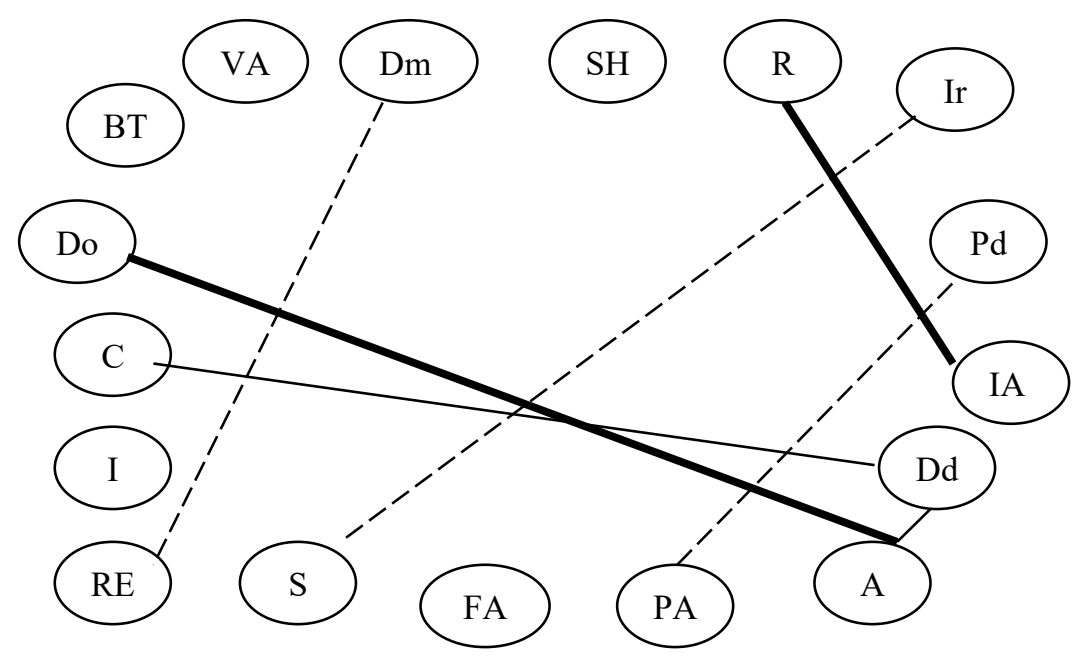

Fig. 1. Structural diagram of manifestations of professional deformation of the personality of teachers with a low level of situational reflection. Legend: PA - pedagogical aggression, A - authoritarianism; Dm - demonstrativeness; Dd - didacticity; Pd - professional dogmatism; Do - dominance; I indifference; C - conservatism; RE - role expansionism; SH - social hypocrisy; BT - behavioral transfer; FA - physical aggression; IA - indirect aggression; Ir - irritation; R - resentment; S suspicion; VA - verbal aggression. The bold line indicates correlations that are significant at $p \leq 0,01$; thin line - at $\mathrm{p} \leq 0,05$; solid lines - positive correlations; dashed lines are negative correlations.

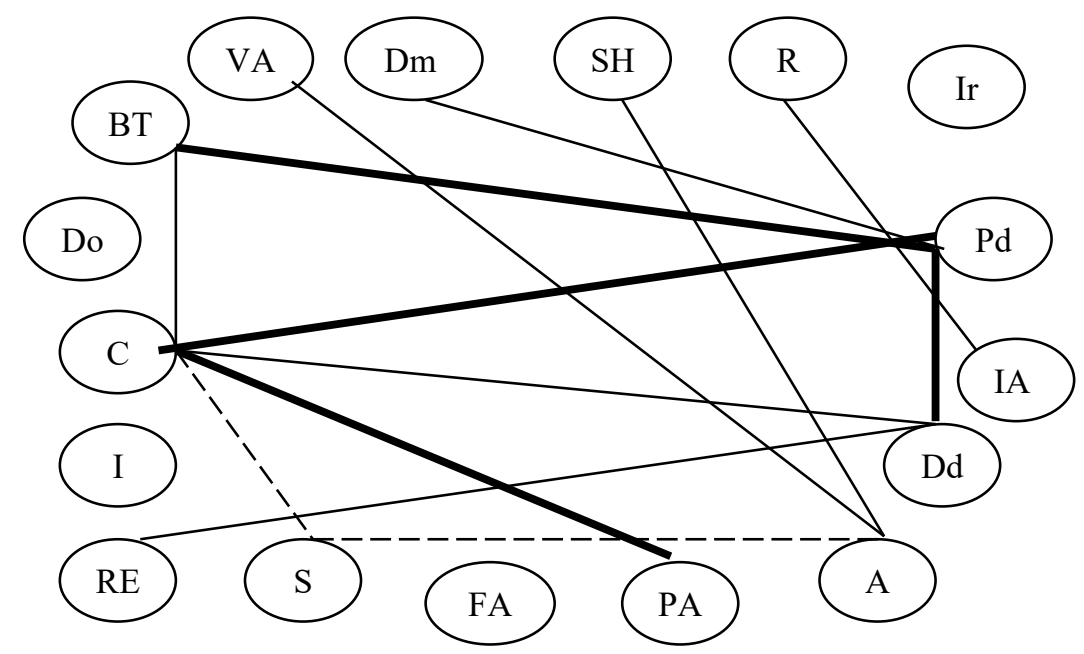

Fig. 2. Structural diagram of manifestations of professional deformation of the personality of teachers with a high level of situational reflection. Legend: the same as in Figure 1. 
It should be noted that for teachers with different levels of situational reflection, such manifestations of professional personality deformation as indifference and physical aggression are not related to other variables. In other words, indifference and physical aggression can be considered as «independent» manifestations of professional personality deformation. In the group of teachers with a low level of situational reflection, the number of connections was found to be 7 , and in the group with a high level of situational reflection, the number of connections was 17.

Based on the data presented, structural organization indices were determined (table 1).

Table 1. The values of the indices of the structural organization of the manifestations of professional deformation of the personality of teachers with different levels of situational reflection.

\begin{tabular}{|l|c|c|}
\hline Indices & $\begin{array}{l}\text { Low level of situational } \\
\text { reflection }\end{array}$ & $\begin{array}{l}\text { High level of } \\
\text { situational reflection }\end{array}$ \\
\hline Structure coherence index & 10 & 35 \\
\hline Structure divergence index & 6 & 4 \\
\hline General organizability index & 16 & 39 \\
\hline
\end{tabular}

The data obtained suggest that the degree of integration (coherence) of the structure of manifestations of professional deformation of the personality is 3,5 times higher in the group of teachers with a high level of situational reflection. For example, a decrease in the level of conservatism leads to a decrease in the level of pedagogical aggression, dogmatism, behavioral transfer, didacticism, authoritarianism; in turn, a decrease in the level of authoritarianism contributes to a decrease in verbal aggression, conservatism, and social hypocrisy (lower indicators of conservatism and authoritarianism are found in the group with a high level of situational reflection). In this regard, it can be argued that in the structure of the manifestations of professional personality deformation of teachers with a high level of situational reflection, the components are more «cohesive», and a decrease in some manifestations of professional personality deformation leads to a decrease in others (except for suspicion, dominance, and irritation).

According to the degree of divergence, the structures of groups with different levels of situational reflection do not differ. It is noteworthy that in the group with a high level of situational reflection, negative associations of suspicion with authoritarianism and conservatism were found. And although, in this study, the level of statistical significance of differences in the level of suspicion did not reach $(p=0,151)$, nevertheless, a higher average rank for this indicator was found in the group of teachers with a high level of situational reflection.

We emphasize that among teachers with a high level of situational reflection, the integrative mechanisms of the structure prevail over the disintegrative ones.

Based on the presented structuralgrams, the basic components were established in the structure of the manifestations of professional personality deformation of teachers with low and high level of situational reflection, which are presented in table 2.

Table 2. Weighted values of manifestations of professional deformation of the personality of teachers with different levels of situational reflection.

\begin{tabular}{|l|c|c|}
\hline Manifestations of professional & \multicolumn{2}{|c|}{ Component weight (W) } \\
\cline { 2 - 3 } $\begin{array}{l}\text { deformation of the personality of } \\
\text { teachers }\end{array}$ & $\begin{array}{l}\text { Low level of situational } \\
\text { reflection }\end{array}$ & $\begin{array}{l}\text { High level of } \\
\text { situational reflection }\end{array}$ \\
\hline Educational aggression & 2 & 10 \\
\hline Authoritarianism & 5 & 8 \\
\hline
\end{tabular}




\begin{tabular}{|l|c|c|}
\hline Demonstration & 2 & 4 \\
\hline Didacticism & 4 & 7 \\
\hline Dogmatism & 2 & 13 \\
\hline Dominance & 3 & 0 \\
\hline Indifference & 0 & 0 \\
\hline Conservatism & 2 & 14 \\
\hline Role expansionism & 2 & 2 \\
\hline Social hypocrisy & 0 & 2 \\
\hline Behavioral Transfer & 0 & 8 \\
\hline Physical aggression & 0 & 0 \\
\hline Indirect aggression & 3 & 2 \\
\hline Irritation & 2 & 0 \\
\hline Resentment & 3 & 2 \\
\hline Suspicion & 2 & 4 \\
\hline Verbal aggression & 0 & 2 \\
\hline
\end{tabular}

As can be seen from table 2, the basic components that ensure the structural integration of the system of manifestations of professional deformation of the personality of teachers with a high level of situational reflection are: conservatism $(\mathrm{W}=14)$, dogmatism $(\mathrm{W}=13)$. It is important to note that a negative relationship between situational reflection and conservatism has been identified [5]. In the group with a low level of situational reflection, no basic components were found.

To identify qualitative differences in the obtained structural patterns by their homogeneity-heterogeneity, the «express- $x^{2}$ » method was used. Comparison of the intercorrelation matrices revealed statistically insignificant differences $(p=0,420)$. Consequently, the structures of the manifestations of professional personality deformation of teachers with low and high levels of situational reflection are heterogeneous, that is, heterogeneous in the content of the relationships within the compared structures.

The results of an empirical study show that lower values of dominance, authoritarianism, social hypocrisy, conservatism and didacticity were found in teachers with a high level of situational reflection. The structure of the manifestations of professional deformation of the personality of teachers with a low level of situational reflection is characterized by a low degree of integration of its components. For teachers with a high level of situational reflection, on the contrary, the structure of the manifestations of professional personality deformation is more consistent, "cohesive», a decrease in some manifestations of professional personality deformation (in particular, conservatism, didacticism, authoritarianism) leads to a decrease in others, which can be used in practice activities for the development of programs for the prevention and correction of manifestations of professional deformation of the personality of teachers.

\section{References}

1. E.F. Seer, E.E. Symanyuk, Psychology of occupational destructions (Ekaterinburg: Business Book, 2005)

2. O.S. Nozhenkina, Eurasian Scientific Association, 2, 150-152 (2015)

3. A.V. Karpov, Psychological Journal, 24(5), (2003)

4. G.N. Uvarova, Professional personality deformation of nurses of various profiles: monograph (Publishing House of the Southern Federal University, Rostov-on-Don 2014) 
5. G.N. Uvarova, M.A. Targonya, Scientific discussion: issues of pedagogy and psychology. 2 (59), (2017) 